\title{
Aspects Regarding the Ornamental Japanese Carp Rearing into Recirculating Systems Conditions
}

\author{
Aurelia NICA*, Lorena DEDIU \\ Faculty of Food Science and Engineering, University "Dunărea de Jos” Galaţi \\ 47 Domnească Street, Galati, Romania \\ *Corresponding author, email: anica@ugal.ro
}

Bulletin UASVM Animal Science and Biotechnologies 71(2) / 2014,

Print ISSN 1843-5262; Electronic ISSN 1843-536X

DOI: $10.15835 /$ buasvmcn-asb:10420

\begin{abstract}
To test the effect of different stocking on their growth, survival rate and number of marketable fish, juveniles of koi carp ( $0.4 \mathrm{~g}$ ), Cyprinus carpio vr. Koi were cultured for 30 days in $200 \mathrm{~L}$ aquariums with densities of 150 exemplars and 300 exemplars respectively. Experiment was conducted in a recirculating system equipped with independent units for mechanical and biological filtration. At the end of the experiment, the data were processed in order to develop a model of growth and determination of the appropriate equation. In terms of growth, Anova test reveals significant differences among the four experimental groups regarding individual final weight, which is determined by the variability of the populations tested intragroup variability as evidenced by the coefficient of variation ( $>50 \%$ for all experimental variants) and the distributions of individual body weight evidenced by the chart type "box and whiskers" which can be seen a large number of extreme values. Technological efficiency did not follow a pattern directly correlated with stocking density, so the differences are practical dictated by the heterogeneity of the population, which has resulted in significant differences in size between individuals and the manifestation of the phenomenon of cannibalism. More researches are still needed to further optimize stocking density of Japanese Ornamental Carp in recirculating system.
\end{abstract}

Keywords: density, ornamental carp, recirculating system

Introduction. The ornamental fish represents a special attraction for a numerous public. In big aquariums but, also, in small personal arrangements, many species with small body size are growing in a great variety of colors. The ornamental Japanese carp „koi carp” is growing in the Asian countries since over 2500 years. Koi carp (Cyprinus carpio koi) is raised all over the world, especially in Japan, as an ornamental variety of common carp (Balon, 1995).

Aims and objectives. The development of intensive aquaculture and thus recirculating production systems is a consequence of the need to intensify as a result of reduced access to land surface correlated with demand for fish continues to increase, the consumer market (Cristea et al., 2002). This study was conducted to determine the influence of density on the growth rate at ju- venile of Japanese ornamental carp grown in recirculating system conditions.

Materials and methods. The used biological material was obtained by artificial reproduction with hormonal stimulation using carp pituitary extract. Recirculating system was adapted by applying mosquito net, avoiding the crossing of fish under the exhaust outlet. In both experimental variants fish were fed with the Advance 1P feed, using a daily intake of $10 \mathrm{~g} / \mathrm{kg}$ metabolic or $4.8 \%$ of the total biomass. The chemical composition of the feed is following: $46 \%$ crude protein, $20 \%$ fat, $2.8 \%$ cellulose, $6.8 \%$ ash and $0.9 \%$ phosphorus.

Results and discussion. Differences among groups at the beginning of the experiment reveals a homogeneous distribution of lots confirmed by Kolmogorov-Smirnov test $(p>0.05)$, which highlighted insignificant differences in the distri- 


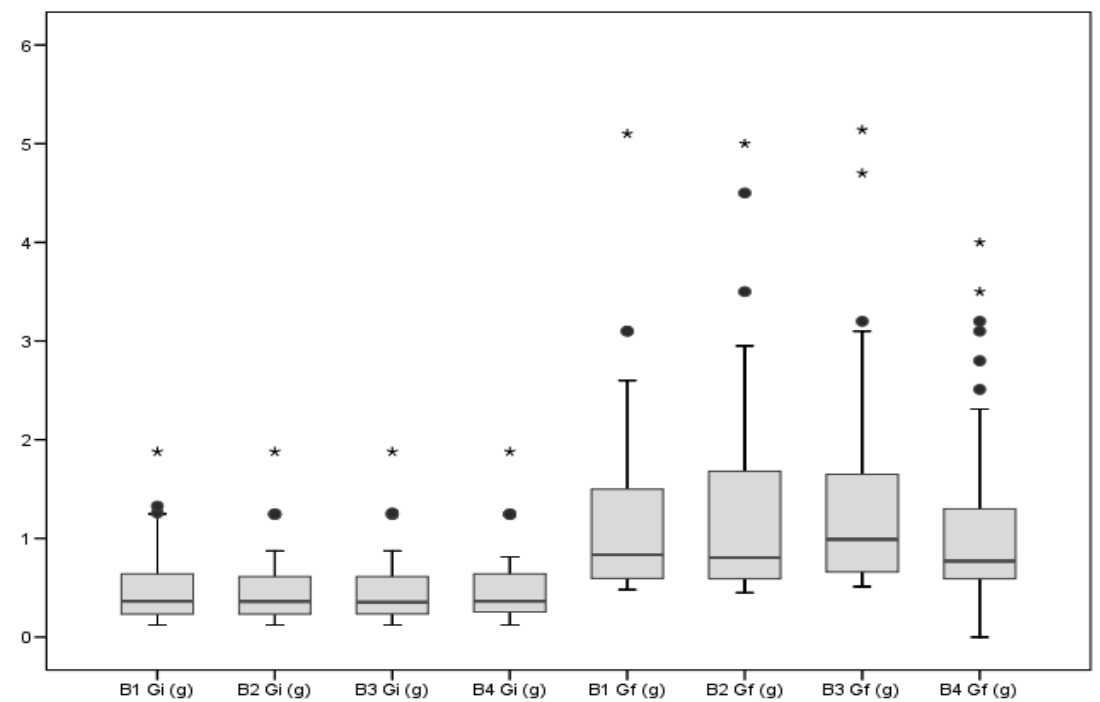

Fig. 1. Statistical indicators for assessing the distribution of intragroup (median, quartile range, extreme)

butions of populations variants experiments to a normal distribution (Poisson). Also, at the start of experiment, the $t$ test pairs using for variables were revealed differences statistically insignificant among measurements of individual weight in both experimental variants.

In terms of growth, Anova test reveals significant differences among the four experimental groups regarding individual final weight, which is determined by the variability of the populations tested intragroup variability as evidenced by the coefficient of variation $(>50 \%$ for all experimental variants) and the distributions of individual body weight evidenced by the chart type "box and whiskers" which can be seen a large number of extreme values (Fig. 1).

These results confirm the technological performance indicators obtained from experimentation. Thus, we can see that there is a model of technological efficiency directly correlated with stocking density differences are basically dictated by intragroup variability, which led, moreover, and in inducing of the phenomenon of cannibalism. At the end of the experiment, the data were processed in order to develop a growth model and determine an appropriate equation of growth. Estimation of growth curve model was made with "power" fish farming is defined by the relation $\mathrm{W}=\mathrm{aL}^{\mathrm{b}}$. The model was tested with ANOVA test result, in conjunction with the high degree of confidence in the regression $(\mathrm{R} 2=0.96)$, confirming the validity of the estimate.

Conclusion. In the present research work, we investigated the influence of density on the growth rate in juvenile Japanese ornamental carp grown in recirculating system conditions. Technological efficiency did not follow a pattern directly correlated with stocking density, so the differences are practical dictated by the heterogeneity of the population, which has resulted in significant differences in size among individuals and the manifestation of the phenomenon of cannibalism. More researches are still needed to further optimize stocking density of Japanese Ornamental Carp in recirculating system.

\section{REFERENCES}

1. Balon EK (1995). Origin and domestication of the wild carp, Cyprinus carpio - from Roman gourmets to the swimming flowers in Aquaculture, 129, 3-48.

2. Cristea V, Grecu I, Ceapa C (2002). Recirculating aquaculture systems engineering, Didactic and Pedagogic Publishing House, Bucharest. 